\title{
When a simulation laboratory becomes essential
}

\author{
Vincent Conti, MD, and Alexander Perez, MD
}

From the Department of Surgery, University of Texas Medical Branch, Galveston, Tex.

Disclosures: Authors have nothing to disclose with regard to commercial support.

Received for publication Sept 18, 2017; accepted for publication Sept 27, 2017; available ahead of print Oct 28, 2017.

Address for reprints: Vincent Conti, MD, Division of Cardiothoracic Surgery, University of Texas Medical Branch, 301 University Blvd, Galveston, TX 77555-0528 (E-mail: vconti@utmb.edu).

J Thorac Cardiovasc Surg 2018;155:156

$0022-5223 / \$ 36.00$

Copyright $(2) 2017$ by The American Association for Thoracic Surgery

https://doi.org/10.1016/j.jtcvs.2017.09.122

New techniques, including minimally invasive approaches, have in the past most frequently been directly brought to the clinical operating room and tried on individual patients. With the introduction of the cardioscopic intervention described in the study of Leopaldi ${ }^{1}$ in this issue of the Journal and in another recent laboratory study used on the closed, beating heart, ${ }^{2}$ the value of making available a training facility as described in the article documenting the experience with the dynamic cardiac biosimulator becomes very clear, and its implementation before clinical use on patients seems essential. Surgical training today, with the increasing use of laparoscopic, thoracoscopic, and robotic interventions, has been greatly enhanced by the implementation of simulation laboratories. The requirement that cardiothoracic residency programs provide a minimum of 20 hours of simulation training to qualify for certification of the American Board of Thoracic Surgery highlights the importance of this enhanced laboratory training. With the introduction of this closed cardiac beating-heart repair for mitral valve leaflet prolapse from chordal rupture and the initiation of the randomized US ReChord clinical trial comparing this cardioscopic technique with standard open repair on cardiopulmonary bypass, training practicing cardiac surgeons on the new technique before clinical implementation in the randomized trial becomes paramount.

Our team and institution at the University of Texas Medical Branch have been dedicated to the development of simulation as a research and educational tool to improve clinical outcomes for many years. ${ }^{3-5}$ In our simulation center, LSTAR (Laboratory for Surgical Training, Assessment, and Research), we are currently using a similar high-fidelity cardioscopic model to improve the instrumentation and surgical approach for various procedures.

As the Leopaldi and colleagues ${ }^{1}$ point out, the limitations of the study presented are that definitive metrics documenting the efficacy of the cardioscopic procedure training were

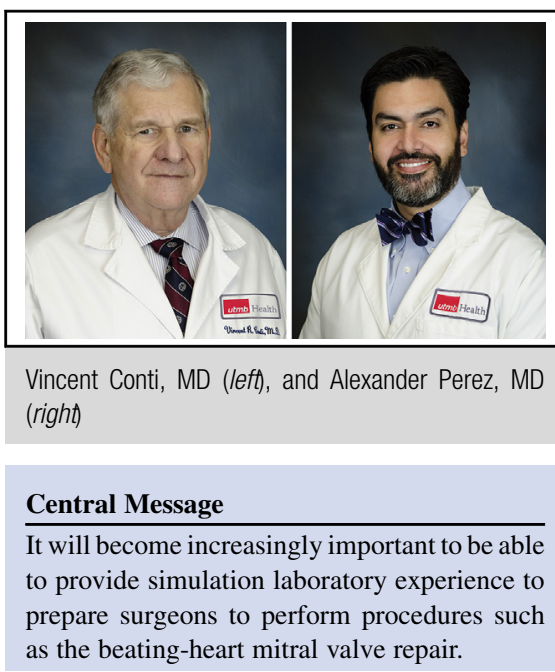

See Article page 147. not well documented, although it was the opinion of the trainers that the laboratory experience was successful in achieving their goal. It was also noted that an obvious limitation of the chordal replacement-only procedure was that no annuloplasty, such as is almost always included with open procedures currently done, could be performed. The US ReChord trial is therefore assumed to be limited to patients without mitral annular dilatation. With the high success rate and low risk currently seen with open mitral repair procedures, this new cardioscopic procedure will have to achieve excellent results to justify replacing the standard approach.

\section{References}

1. Leopaldi AM, Wrobel K, Speziali G, van Tuijl S, Drasutiene A, Chitwood WR Jr. The dynamic cardiac biosimulator: a method for training physicians in beating-heart mitral valve repair procedures. J Thorac Cardiovasc Surg. 2018; 155:147-55.

2. Rosa B, Machaidze Z, Mencattelli M, Manjila S, Shin B, Price K, et al. Cardioscopically guided beating heart surgery: paravalvular leak repair. Ann Thorac Surg. 2017; 104:1074-9.

3. Gaba DM, DeAnda A. A comprehensive anesthesia simulation environment: recreating the operating room for research and training. Anesthesiology. 1988;69: 387-94.

4. Diesen DL, Erhunmwunsee L, Bennett KM, Ben-David K, Yurcisin B, Ceppa EP, et al. Effectiveness of laparoscopic computer simulator versus usage of box trainer for endoscopic surgery training of novices. J Surg Educ. 2011;68:282-9.

5. Brown KM, Paige JT. Simulation in Surgical Training and ractice. Preface. Surg Clin North Am. 2015;95:xvii-xviii. 